Annals of Pure and Applied Mathematics

Vol. 13, No. 2, 2017, 173-183

ISSN: 2279-087X (P), 2279-0888(online)

Published on 4 April 2017

Annals of

www.researchmathsci.org

DOI: http://dx.doi.org/10.22457/apam.v13n2a3

Pure and Applied

Mathematics

\title{
Adjacent Vertex Distinguishing Total Coloring of Line and Splitting Graph of Some Graphs
}

\author{
K.Thirusang $u^{1}$ and R.Ezhilarasi ${ }^{2}$ \\ ${ }^{1}$ Department of Mathematics, S.I.V.E.T College, Gowrivakkam \\ Chennai - 600 073, India \\ ${ }^{2}$ Ramanujan Institute for Advanced Study in Mathematics \\ University of Madras, Chennai - 600 005, India. \\ ${ }^{2}$ Corresponding author. Email: ezhilmath@gmail.com; ezhilarasi@unom.ac.in
}

Received 9 March 2017; accepted 28 March 2017

Abstract. In this paper, we prove the existence of the adjacent vertex distinguishing total coloring of line graph of Fan graph $F_{n}$, double star $K_{1, n, n}$, Friendship graph $F^{n}$ and splitting graph of path $P_{n}$, cycle $C_{n}$, star $K_{1, n}$ and sun let graph $S^{2 n}$ in detail.

Keywords: simple graph, adjacent vertex distinguishing total coloring, line graph, splitting graph, path, cycle, star, sun let, fan, double star and friendship graph.

AMS Mathematics Subject Classification (2010): 05C15, 05C38, 05 C76

\section{Introduction}

Throughout this paper, we consider finite, simple, connected and undirected graph $G=(V(G), E(G))$. For every vertex $u, v \in V(G)$, the edge connecting two vertices is denoted by $u v \in E(G)$. For all other standard concepts of graph theory, we see [1,2,5]. For graphs $G_{1}$ and $G_{2}$, we let $G_{1} \cup G_{2}$ denotes their union, that is, $V\left(G_{1} \cup G_{2}\right)=V\left(G_{1}\right) \cup V\left(G_{2}\right)$ and $E\left(G_{1} \cup G_{2}\right)=E\left(G_{1}\right) \cup E\left(G_{2}\right)$. If a simple graph G has two adjacent vertices of maximum degree, then $\psi_{\text {avt }}(G) \geq \Delta(G)+2$. Otherwise, if a simple graph $\mathrm{G}$ does not have two adjacent vertices of maximum degree, then $\psi_{\text {avt }}(G)=\Delta(G)+1$. The well-known $A V D T C$ conjecture, made by Zhang et al. [8] says that every simple graph $G$ has $\chi_{\text {avt }}(G) \leq \Delta(G)+3$. AVDTC of tensor product of graphs are discussed in litrature [6,7]. $(2,1)$-total labelling of cactus graphs and adjacent vertex distinguishing edge colouring of cactus graphs are discussed in literature $[3,4]$. Throughout the paper, we denote the path graph, cycle graph, complete graph, star graph, sun let, fan graph, double star and friendship graph by $P_{n}, C_{n}, K_{n}, K_{1, n}, S^{2 n}, F_{n}$, $K_{1, n}$ and $F^{n}$ respectively. A proper total coloring of $G$ is an assignment of colors to the vertices and the edges such that no two adjacent vertices and adjacent edges are assigned with the same color, no edge and its end vertices are assigned with the same color and for 
K.Thirusangu and R.Ezhilarasi

any pair of adjacent vertices have distinct set of colors.

A total $k$-coloring of the graph $G$ is adjacent vertex distinguishing, if a mapping $f: V(G) \cup E(G) \rightarrow\{1,2, \cdots, k\}, k \in \mathbb{Z}^{+}$such that any two adjacent or incident elements in $V(G) \cup E(G)$ have different colors. The minimum number of colors required to give an adjacent vertex distinguishing total coloring (abbreviated as AVDTC) to the graph $G$ is denoted by $\chi_{\text {avt }}(G)$.

First, we find the adjacent vertex distinguishing total chromatic number of Fan graph, double star graph, Friendship graph and complete graph.

Proposition 1.1. $\chi_{\text {avt }}\left(F_{n}\right)=n+1, n>3$.

Proof: Fan graph denoted by $F_{n}$, is a graph obtained by joining all vertices of the path $P_{n}$ to a further vertex called the center vertex $v$. Thus $F_{n}$ contains $n+1$ vertices and $2 n-1$ edges. Here, we have the vertex and edge set $V\left(F_{n}\right)=\left\{v, v_{1}, v_{2}, \cdots, v_{n}\right\}$ and $E\left[F_{n}\right]=\left\{\left(\bigcup_{i=1}^{n} v v_{i}\right) \cup\left(\bigcup_{i=1}^{n-1} v_{i} v_{i+1}\right)\right\}$. Now we define $f: V\left(F_{n}\right) \cup E\left(F_{n}\right) \rightarrow\{1,2, \cdots, k\}$ given by,

$$
\begin{aligned}
& \text { For } 1 \leq i \leq n, \quad f\left(v_{i}\right)=i \text { and } f(v)=n+1 \\
& \text { For } 1 \leq i \leq n-1, \quad f\left(v_{i} v_{i+1}\right)=i+2 \operatorname{and} f\left(v v_{1}\right)=n \\
& \text { For } 2 \leq i \leq n, \quad f\left(v_{i} v_{n}\right)=i-1 \\
& \therefore \quad \chi_{\text {avt }}\left(F_{n}\right)=n+1, n>3 .
\end{aligned}
$$

Proposition 1.2. $\left.\chi_{a v t}\left(K_{1, n, n}\right)\right)=n+1$, for $n>2$.

Proof: The double star $K_{1, n, n}$ is obtained from the star $K_{1, n}$ by adding a new pendent edge of the existing $n$ pendent vertices. Here $v$ is the apex vertex. The vertex set and edge set of $K_{1, n, n}$ as follows,

$$
V\left[K_{1, n, n}\right]=\left\{\left(\bigcup_{i=1}^{n} v \cup v_{i} \cup v_{i}^{\prime}\right)\right\} \text { and } E\left[K_{1, n, n}\right]=\left\{\left(\bigcup_{i=1}^{n}\left(v v_{i} \cup v_{i} v_{i}^{\prime}\right)\right)\right\}
$$

Then $\left|V\left(K_{1, n, n}\right)\right|=2 n+1$ and $\left|E\left(K_{1, n, n}\right)\right|=2 n$. We define

$f: V\left(K_{1, n, n}\right) \cup E\left(K_{1, n, n}\right) \rightarrow\{1,2, \cdots, k\}$ given by

$f(v)=n+1, f\left(v v_{n}\right)=1, f\left(v_{n-1} v_{n-1}^{\prime}\right)=1 \operatorname{and} f\left(v_{n} v_{n}^{\prime}\right)=2$.

For $1 \leq i \leq n, f\left(v_{i}\right)=\operatorname{iand} f\left(v_{i}^{\prime}\right)=n+1$,

For $1 \leq i \leq n-1, f\left(v v_{i}\right)=i+1$

For $1 \leq i \leq n-2, f\left(v_{i} v_{i}^{\prime}\right)=i+2$.

$$
\left.\therefore \quad \chi_{a v t}\left(K_{1, n, n}\right)\right)=n+1 \text {, for } n>2 \text {. }
$$

Proposition 1.3. $\chi_{\text {avt }}\left(F^{n}\right)=2 n+1, n \geq 2$. 
Adjacent Vertex Distinguishing Total Coloring of Line and Splitting Graph of Some Graphs

Proof: The friendship graph $F^{n}$ can be constructed by joining $n$ copies of the cycle graph $C_{3}$ with a common vertex say $v$. Thus, the vertex set and edge set are $\left\{v, v_{1}, v_{2}, \cdots, v_{2 n}\right\}$ and $E\left[F^{n}\right]=\left\{\left(\bigcup_{i=1}^{2 n} v v_{i}\right) \cup\left(\bigcup_{i=1}^{n} v_{2 i-1} v_{2 i}\right)\right\}$. Here $\left|V\left(F^{n}\right)\right|=2 n+1$ and $\left|E\left(F^{n}\right)\right|=3 n$. Now we define $f: V\left(F^{n}\right) \cup E\left(F^{n}\right) \rightarrow\{1,2, \cdots, k\}$ given by for $n \geq 2$, For $1 \leq i \leq n$,

$$
\begin{aligned}
& f\left(v_{2 i-1}\right)=2, f\left(v_{2 i}\right)=3, f\left(v v_{2 i-1}\right)=2 i-1, f\left(v v_{2 i}\right)=2 i \text { and } f(v)=f\left(v_{2 i-1} v_{2 i}\right)=2 n+1 . \\
& \therefore \quad \chi_{\text {avt }}\left(F^{n}\right)=2 n+1, n \geq 2 .
\end{aligned}
$$

Proposition 1.4. The complete graph $K_{n}$ admits AVDTC and

$$
\chi_{\text {avt }}\left(K_{n}\right)= \begin{cases}n+1, & \text { if } n \equiv 0(\bmod 2) \\ n+2, & \text { if } n \equiv 1(\bmod 2)\end{cases}
$$

Proof: Let $x_{1}, x_{2}, \cdots x_{n}$ be the vertices of complete graph $K_{n}$. We define $f: V\left(K_{n}\right) \cup E\left(K_{n}\right) \rightarrow\{1,2, \cdots, k\}$ given by

Case-1 When $n \equiv 0(\bmod 2)$

For $1 \leq i, j \leq n$

$$
\begin{aligned}
f\left(x_{i}\right) & = \\
f\left(x_{i} x_{j}\right) & =i+j, \text { if } i+j=n+1
\end{aligned}
$$

For $i+j \neq n+1$

$$
f\left(x_{i} x_{j}\right) \equiv\left\{\begin{aligned}
\frac{i+j}{2}, & \text { if } i+j \equiv 0(\bmod 2) \\
\left(\left\lceil\frac{n+1}{2}\right](i+j)\right)(\bmod n+1), & \text { if } i+j \equiv 1(\bmod 2)
\end{aligned}\right.
$$

Case-2 When $n \equiv 1(\bmod 2)$

For $1 \leq i, j \leq n$

$$
\begin{array}{rlr}
f\left(x_{i}\right) & = & i, \\
f\left(x_{i} x_{j}\right) & = & i+j, \text { if } i+j=n+2
\end{array}
$$

For $i+j \neq n+2$

$$
\begin{aligned}
& f\left(x_{i} x_{j}\right) \equiv\left\{\begin{aligned}
\frac{i+j}{2}, & \text { if } i+j \equiv 0(\bmod 2) \\
\left(\left\lceil\frac{n+2}{2}\right\rceil(i+j)\right)(\bmod n+2), & \text { if } i+j \equiv 1(\bmod 2)
\end{aligned}\right. \\
& \therefore \chi_{\text {avt }}\left(K_{n}\right)= \begin{cases}n+1, & \text { if } n \equiv 0(\bmod 2) \\
n+2, & \text { if } n \equiv 1(\bmod 2)\end{cases}
\end{aligned}
$$




\section{K.Thirusangu and R.Ezhilarasi}

We observe that these graphs are admits the adjacent vertex distinguishing total coloring conjecture. Next, we discuss the line graph of these graphs admits AVDTC conjecture.

\section{AVDTC of line graph}

A graph $G$ and its line graph $L(G)$ is a graph such that each vertex of $L(G)$ represents an edge of $G$ and two vertices of $L(G)$ are adjacent iff their corresponding edges are adjacent in $G$. In this section, the adjacent vertex distinguishing total coloring of line graph of Fan graph $L\left(F_{n}\right)$, double star $L\left(K_{1, n, n}\right)$ and Friendship graph $L\left(F^{n}\right)$ are discussed.

Theorem 2.1. The line graph of Fan graph $L\left(F_{n}\right)$ admits $A V D T C$ and

$$
\chi_{\text {avt }} L\left(F_{n}\right)=n+3 \text {, for } n>3
$$

Proof: From the proposition (1.1), Let us consider the edges of $F_{n}$ as $v v_{i}=x_{i}$, for $1 \leq i \leq n$ and $v_{i} v_{i+1}=y_{i}$, for $1 \leq i \leq n-1$.

$$
V\left[L\left(F_{n}\right)\right]=\left\{\left(\bigcup_{i=1}^{n} x_{i}\right) \cup\left(\bigcup_{i=1}^{n-1} y_{i}\right)\right\}
$$

Hence $\left|V\left(L\left(F_{n}\right)\right)\right|=2 n-1$ and $\left|E\left(L\left(F_{n}\right)\right)\right|=\frac{n^{2}+5 n-8}{2}$. Note that $\left\{x_{1}, x_{2}, \cdots, x_{n}\right\}$ forms the complete graph $K_{n}$ with $n$ vertices. Now we define $f: V\left(L\left(F_{n}\right)\right) \cup E\left(L\left(F_{n}\right)\right) \rightarrow\{1,2, \cdots, k\}$ as follows. For this, first we color a clique in $L\left(F_{n}\right)$ using the proposition (1.4). Now the remaining vertices and edges of $L\left(F_{n}\right)$ are colored as follows.

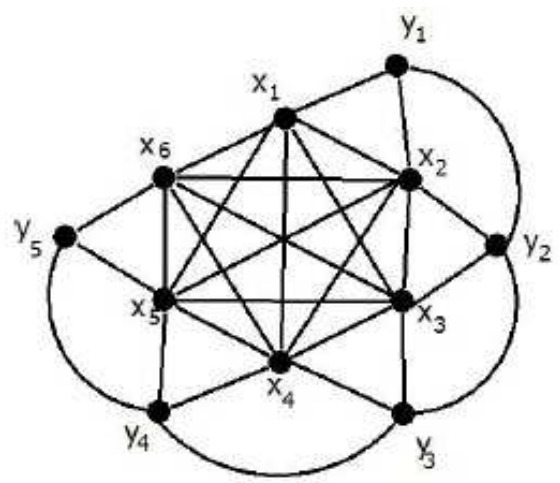

Figure 1: $L\left(F_{6}\right)$

Case-1. When $n$ is even.

For $1 \leq i \leq n-1, \quad f\left(x_{i} y_{i}\right)=n+2 ; f\left(x_{i+1} y_{i}\right)=n+3 ; f\left(y_{i}\right)=f\left(x_{i} x_{i+1}\right)$; 
Adjacent Vertex Distinguishing Total Coloring of Line and Splitting Graph of Some Graphs

For $1 \leq i \leq n-2, \quad f\left(y_{i} y_{i+1}\right)=i+1$.

Case-2. When $n$ is odd.

For $1 \leq i \leq n-1, \quad f\left(x_{i} x_{i+1}\right)=f\left(y_{i}\right) ; f\left(x_{i+1} y_{i}\right)=n+3$;

For $1 \leq i \leq n-2, \quad f\left(y_{i} y_{i+1}\right)=i+1$,

For $1 \leq i \leq\left\lfloor\frac{n}{2}\right\rfloor, \quad f\left(x_{2 i} y_{2 i}\right)=i ; f\left(x_{2 i-1} y_{2 i-1}\right)=\left\lceil\frac{n}{2}\right\rceil+i$.

Hence Line graph of fan graph admits AVDTC.

$$
\therefore \quad \chi_{\text {avt }}\left(L\left(F_{n}\right)\right)=n+3 \text {. Hence the theorem. }
$$

Theorem 2.2. The line graph of double star graph $L\left(K_{1, n, n}\right)$ admits $A V D T C$ and

$$
\chi_{\text {avt }} L\left(K_{1, n, n}\right)=n+2 \text {, for } n>3 \text {. }
$$

Proof: From the proposition (1.2), Let us consider the edges of $K_{1, n, n}$ as $v v_{i}=x_{i}$ and $v_{i} v_{i}^{\prime}=y_{i}$ for $1 \leq i \leq n . V\left[L\left(K_{1, n, n}\right)\right]=\left\{\bigcup_{i=1}^{n}\left(x_{i} \cup y_{i}\right)\right\}$ Hence $\left|V\left(L\left(K_{1, n, n}\right)\right)\right|=2 n$ and $\left|E\left(L\left(K_{1, n, n}\right)\right)\right|=\frac{n^{2}+n}{2}$. Note that $\left\{x_{1}, x_{2}, \cdots, x_{n}\right\}$ forms the complete graph $K_{n}$ with $n$ vertices. Now we define $f: V\left(L\left(K_{1, n, n}\right)\right) \cup E\left(L\left(K_{1, n, n}\right)\right) \rightarrow\{1,2, \cdots, k\}$ as follows. For this, first we color a clique in $L\left(K_{1, n, n}\right)$ using the proposition (1.4). Now the remaining vertices and edges are colored as follows.

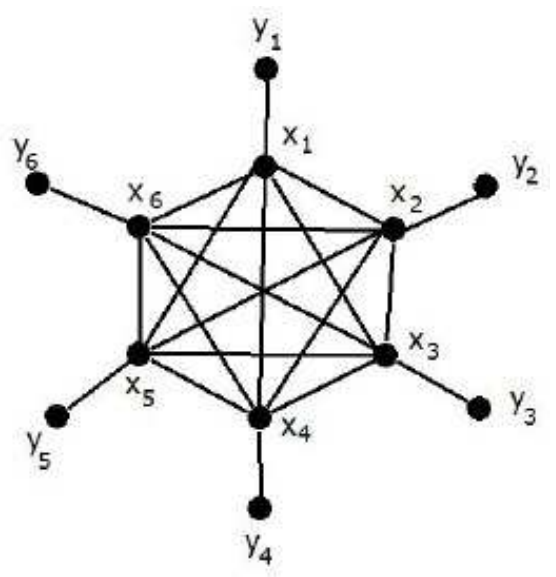

Figure 2: $L\left(K_{1,6,6}\right)$

Case-1. When $n$ is even.

For $1 \leq i \leq n, \quad f\left(x_{i} y_{i}\right)=n+2 ; f\left(y_{i}\right)=n+1$. 
Case-2. When $n$ is odd.

For $1 \leq i \leq n, \quad f\left(y_{i}\right)=n+2$. For $1 \leq i \leq\left\lfloor\frac{n}{2}\right\rfloor, \quad f\left(x_{2 i} y_{2 i}\right)=i$.

For $1 \leq i \leq\left\lceil\frac{n}{2}\right\rceil, \quad f\left(x_{2 i-1} y_{2 i-1}\right)=\left\lceil\frac{n}{2}\right\rceil+i$.

Hence the Line graph of double star admits AVDTC.

$\therefore \quad \chi_{\text {avt }}\left(L\left(K_{1, n, n}\right)\right)=n+2$. Hence the theorem.

Theorem 2.3. The line graph of friendship graph $L\left(F^{n}\right)$ admits $A V D T C$ and

$$
\chi_{\text {avt }} L\left(F^{n}\right)=2 n+3 \text {, for } n \geq 2
$$

Proof: From the proposition (1.3), Let us consider the edges of $F^{n}$ as $v_{2 i-1} v_{2 i}=y_{i}$, for $1 \leq i \leq 2 n$ and $v v_{i}=x_{i}$, for $1 \leq i \leq n$.

$$
V\left[L\left(F^{n}\right)\right]=\left\{\left(\bigcup_{i=1}^{n} y_{i}\right) \cup\left(\bigcup_{i=1}^{2 n} x_{i}\right)\right\}
$$

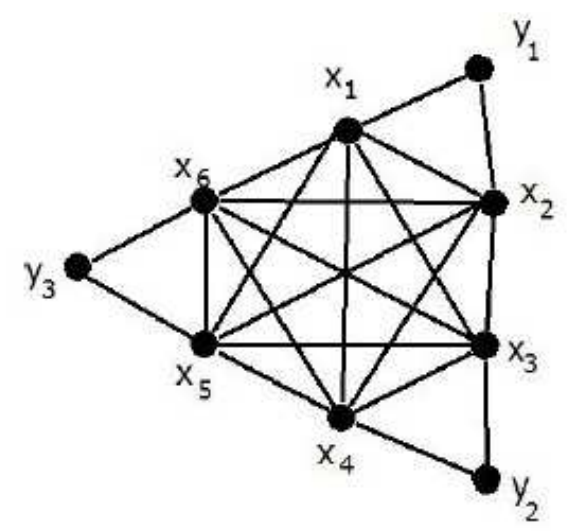

Figure 3: $L\left(F^{3}\right)$

Hence $\left|V\left(L\left(F^{n}\right)\right)\right|=3 n \quad$ and $\quad\left|E\left(L\left(F^{n}\right)\right)\right|=n(2 n+1)$. Note that $\left\{x_{1}, x_{2}, \cdots, x_{2 n}\right\}$ forms the complete graph $K_{2 n}$ with $2 n$ vertices and $x_{2 i-1}$ and $x_{2 i}$ are adjacent with $y_{i}$ for $1 \leq i \leq n$. Now we define

$f: V\left(L\left(F^{n}\right)\right) \cup E\left(L\left(F^{n}\right)\right) \rightarrow\{1,2, \cdots, k\}$ as follows. For this, first we color a clique in $L\left(F^{n}\right)$ using the poposition (1.4). The remaining are colored for $1 \leq i \leq n$, $f\left(x_{2 i-1} y_{i}\right)=n+2 ; f\left(x_{2 i} x_{i}\right)=n+3 ; f\left(y_{i}\right)=f\left(x_{2 i-1} x_{2 i}\right)$. Hence the Line graph of friendship graph admits AVDTC. $\quad \therefore \quad \chi_{a v t}\left(L\left(F^{n}\right)\right)=2 n+3$.

\section{AVDTC of splitting graph}

For a graph $G$ the splitting graph of $G$ is obtained by adding a new vertex $v^{\prime}$ 
Adjacent Vertex Distinguishing Total Coloring of Line and Splitting Graph of Some Graphs

corresponding to each vertex $v$ of $G$ such that $N(v)=N\left(v^{\prime}\right)$. The resultant graph is denoted as $\operatorname{Sp}(G)$. In this section, the adjacent vertex distinguishing total coloring of Splitting graph of path $P_{n}$, cycle $C_{n}$ and star $K_{1, n}$ and sun let $S^{2 n}$ graphs are discussed.

Theorem 3.1. The splitting graph of path graph $\operatorname{Sp}\left(P_{n}\right)$ admits AVDTC and

$$
\chi_{\text {avt }} \operatorname{Sp}\left(P_{n}\right)=\left\{\begin{array}{l}
6, \text { for } n \geq 4 \\
5, \text { for } n=3
\end{array}\right.
$$

Proof: Let we denote $\left\{v_{1}, v_{2}, \cdots, v_{n}\right\}$ as the vertices of $P_{n}$ and $\left\{v_{1}^{\prime}, v_{2}^{\prime}, \cdots, v_{n}^{\prime}\right\}$ as the new vertices. The vertex set and edge set of $\operatorname{Sp}\left(P_{n}\right)$ are

$$
V\left[S p\left(P_{n}\right)\right]=\left\{\left(\bigcup_{i=1}^{n} v_{i} \cup v_{i}^{\prime}\right)\right\} \text { and } E\left[S p\left(P_{n}\right)\right]=\left\{\left(\bigcup_{i=1}^{n-1}\left(v_{i} v_{i+1} \cup v_{i} v_{i+1}^{\prime} \cup v_{i}^{\prime} v_{i+1}\right)\right)\right\}
$$

Figure 4: $\operatorname{Sp}\left(P_{5}\right)$

Hence $\left|V\left(S p\left(P_{n}\right)\right)\right|=2 n$ and $\left|E\left(S p\left(P_{n}\right)\right)\right|=3(n-1)$. This theorem is trivial for $n=3$. Now we define $f: V\left(\operatorname{Sp}\left(P_{n}\right)\right) \cup E\left(\operatorname{Sp}\left(P_{n}\right)\right) \rightarrow\{1,2, \cdots, k\}$ given by for $n \geq 4$,

$$
\begin{gathered}
\text { For } 1 \leq i \leq n, \quad f\left(v_{i}\right)=f\left(v_{i}^{\prime}\right)=\left\{\begin{array}{l}
\{1\}, \text { if } i \equiv 1(\bmod 2) \\
\{2\}, \text { if } i \equiv 0(\bmod 2)
\end{array}\right. \\
\text { For } 1 \leq i \leq n-1, \quad f\left(v_{i} v_{i+1}\right)=\left\{\begin{array}{l}
\{3\}, \text { if } i \equiv 1(\bmod 2) \\
\{4\}, \text { if } i \equiv 0(\bmod 2)
\end{array}\right. \\
f\left(v_{i} v_{i+1}^{\prime}\right)=5 \text { and } f\left(v_{i}^{\prime} v_{i+1}\right)=6
\end{gathered}
$$

Clearly, the color classes of any two adjacent vertices are different.

$$
\therefore \quad \chi_{a v t}\left(S p\left(P_{n}\right)\right)=6, \quad n \geq 4 \text {. Hence the theorem. }
$$

Theorem 3.2. The splitting graph of cycle graph $\operatorname{Sp}\left(C_{n}\right)$ admits $A V D T C$ and

$$
\chi_{\text {avt }} \operatorname{Sp}\left(C_{n}\right)=6, n \geq 4 .
$$

Proof: Let we denote $\left\{v_{1}, v_{2}, \cdots, v_{n}\right\}$ as the vertices of $C_{n}$ and $\left\{v_{1}^{\prime}, v_{2}^{\prime}, \cdots, v_{n}^{\prime}\right\}$ as the new vertices. The vertex set and edge set of $\operatorname{Sp}\left(C_{n}\right)$ is given by 
K.Thirusangu and R.Ezhilarasi

$$
\begin{aligned}
& V\left[\operatorname{Sp}\left(C_{n}\right)\right]=\left\{\left(\bigcup_{i=1}^{n} v_{i} \cup v_{i}^{\prime}\right)\right\} \text { and } \\
& E\left[\operatorname{Sp}\left(C_{n}\right)\right]=\left\{\left(\bigcup_{i=1}^{n-1}\left(v_{i} v_{i+1} \cup v_{i}^{\prime} v_{i+1} \cup v_{i} v_{i+1}^{\prime}\right)\right) \cup\left(v_{n} v_{1} \cup v_{n}^{\prime} v_{1} \cup v_{n} v_{1}^{\prime}\right)\right\}
\end{aligned}
$$

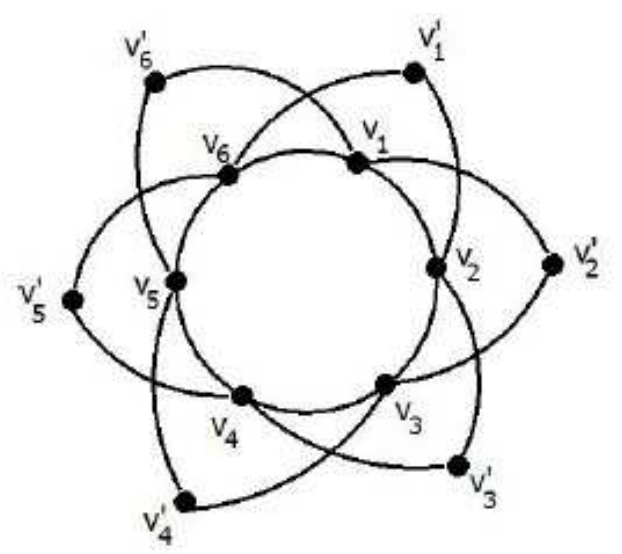

Figure 5: $\operatorname{Sp}\left(C_{6}\right)$

Then $\left|V\left(S p\left(C_{n}\right)\right)\right|=2 n$ and $\left|E\left(S p\left(C_{n}\right)\right)\right|=3 n$.

Define $f: V\left(\operatorname{Sp}\left(C_{n}\right)\right) \cup E\left(\operatorname{Sp}\left(C_{n}\right)\right) \rightarrow\{1,2, \cdots, k\}$ as follows.

Case-1. When $n$ is even.

$$
\begin{gathered}
\text { For } 1 \leq i \leq n, \quad f\left(v_{i}\right)=f\left(v_{i}^{\prime}\right)= \begin{cases}1, & \text { if } i \equiv 1(\bmod 2) \\
2, & \text { if } i \equiv 0(\bmod 2)\end{cases} \\
\text { For } 1 \leq i \leq n-1, \quad f\left(v_{i} v_{i+1}\right)= \begin{cases}3, & \text { if } i \equiv 1(\bmod 2) \\
4, & \text { if } i \equiv 0(\bmod 2)\end{cases} \\
f\left(v_{i}^{\prime} v_{i+1}\right)=f\left(v_{n}^{\prime} v_{1}\right)=6, f\left(v_{i} v_{i+1}^{\prime}\right)=f\left(v_{n} v_{1}^{\prime}\right)=5, \operatorname{and}\left(v_{n} v_{1}\right)=4 .
\end{gathered}
$$

Case-2. When $n$ is odd.

$$
\begin{gathered}
\text { For } 1 \leq i \leq n-1, f\left(v_{i}\right)=f\left(v_{i}^{\prime}\right)= \begin{cases}1, & \text { if } i \equiv 1(\bmod 2) \\
2, & \text { if } i \equiv 0(\bmod 2)\end{cases} \\
\text { For } 1 \leq i \leq n-2, f\left(v_{i} v_{i+1}\right)= \begin{cases}3, & \text { if } i \equiv 1(\bmod 2) \\
4, & \text { if } i \equiv 0(\bmod 2)\end{cases}
\end{gathered}
$$

For $1 \leq i \leq n-1, f\left(v_{i}^{\prime} v_{i+1}\right)=f\left(v_{n}^{\prime} v_{1}\right)=6, f\left(v_{i} v_{i+1}^{\prime}\right)=f\left(v_{n} v_{1}^{\prime}\right)=5, f\left(v_{n}\right)=4$,

$$
f\left(v_{n} v_{1}\right)=2 \text { and } f\left(v_{n-1} v_{n}\right)=1
$$

The color classes of any two adjacent vertices are different. 
Adjacent Vertex Distinguishing Total Coloring of Line and Splitting Graph of Some Graphs

$$
\therefore \quad \chi_{\text {avt }}\left(\operatorname{Sp}\left(C_{n}\right)\right)=6 \text {. }
$$

Hence the theorem.

Theorem 3.3. The splitting graph of star graph $\operatorname{Sp}\left(K_{1, n}\right)$ admits AVDTC and

$$
\chi_{\text {avt }} \operatorname{Sp}\left(K_{1, n}\right)=2 n+1, n \geq 2 .
$$

Proof: Let $\left\{v, v_{1}, v_{2}, \cdots, v_{n}\right\}$ be the vertices of star $K_{1, n}$ and $\left\{v^{\prime}, v_{1}^{\prime}, v_{2}^{\prime}, \cdots, v_{n}^{\prime}\right\}$ be the new vertices of $K_{1, n}$. Here $v$ is the apex vertex. The vertex set and edge set of $\operatorname{Sp}\left(K_{1, n}\right)$ is given by

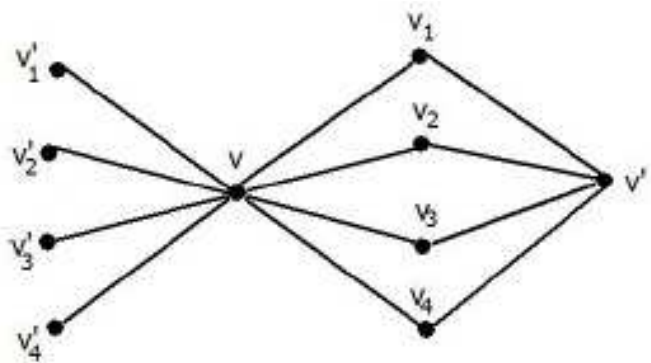

Figure 6: $S p\left(K_{1,4}\right)$

$V\left[S\left(K_{1, n}\right)\right]=\left\{\left(\bigcup_{i=1}^{n} v_{i} \cup v_{i}^{\prime}\right) \cup v \cup v^{\prime}\right\}$ and $E\left[\operatorname{Sp}\left(K_{1, n}\right)\right]=\left\{\bigcup_{i=1}^{n}\left(v v_{i} \cup v v_{i}^{\prime} \cup v^{\prime} v_{i}\right)\right\}$

Then $\left|V\left(\operatorname{Sp}\left(K_{1, n}\right)\right)\right|=2(n+1)$ and $\left|E\left(\operatorname{Sp}\left(K_{1, n}\right)\right)\right|=3 n$.

We define $f: V\left(\operatorname{Sp}\left(K_{1, n}\right)\right) \cup E\left(\operatorname{Sp}\left(K_{1, n}\right)\right) \rightarrow\{1,2, \cdots, k\}$ given by

For $1 \leq i \leq n$,

$$
f\left(v_{i}\right)=f\left(v_{i}^{\prime}\right)=i, f(v)=f\left(v^{\prime}\right)=n+1, f\left(v v_{i}^{\prime}\right)=f\left(v^{\prime} v_{i}\right)=n+1+i
$$

For $1 \leq i \leq n-1$,

$$
f\left(v v_{i}\right)=i+1, f\left(v v_{n}\right)=1
$$

Clearly, the color classes of any two adjacent vertices are different.

$$
\therefore \quad \chi_{a v t}\left(\operatorname{Sp}\left(K_{1, n}\right)\right)=2 n+1, n \geq 2 .
$$

Hence the theorem.

Theorem 3.4. The splitting graph of sun let graph $S^{2 n}$ admits AVDTC and

$$
\chi_{\text {avt }} \operatorname{Sp}\left(S^{2 n}\right)=8, n \geq 4 \text {. }
$$

Proof: Let $\left\{v_{1}, v_{2}, \cdots, v_{n}, v_{1}^{\prime}, v_{2}^{\prime}, \cdots v_{n}^{\prime}\right\}$ be the vertices of sun let graph $S^{2 n}$. Here $\operatorname{deg}\left(v_{i}\right)=3$ and $\operatorname{deg}\left(v_{i}^{\prime}\right)=1$ for $i=1,2, \cdots, n$. Now consider the new vertices $\left\{u_{1}, u_{2}, \cdots, u_{n}, u_{1}^{\prime}, u_{2}^{\prime}, \cdots, u_{n}^{\prime}\right\}$ of $S^{2 n}$. The vertex set and edge set of $\operatorname{Sp}\left(S^{2 n}\right)$ is given by 
K.Thirusangu and R.Ezhilarasi

$$
V\left[S p\left(S^{2 n}\right)\right]=\left\{\left(\bigcup_{i=1}^{n} v_{i} \cup v_{i}^{\prime} \cup u_{i} \cup u_{i}^{\prime}\right)\right\}
$$

$E\left[S p\left(S^{2 n}\right)\right]=\left\{\bigcup_{i=1}^{n-1}\left(v_{i} v_{i+1} \cup v_{i} u_{i+1} \cup v_{i+1} u_{i}\right) \cup \bigcup_{i=1}^{n}\left(v_{i} v_{i}^{\prime} \cup v_{i} u_{i}^{\prime} \cup u_{i} v_{i}^{\prime}\right) \cup\left(v_{n} v_{1} \cup v_{n} u_{1} \cup v_{1} u_{n}\right)\right\}$ Then $\left|V\left(S p\left(S^{2 n}\right)\right)\right|=4 n$ and $\left|E\left(S p\left(S^{2 n}\right)\right)\right|=6 n$.

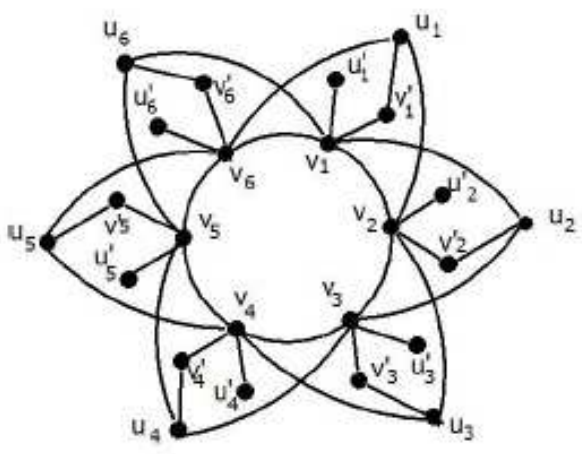

Figure 7: $\operatorname{Sp}\left(S^{6}\right)$

We define $f: V\left(S p\left(S^{2 n}\right)\right) \cup E\left(S p\left(S^{2 n}\right)\right) \rightarrow\{1,2, \cdots, k\}$ given by Case-1. If $n \equiv 1(\bmod 2)$.

For $1 \leq i \leq n-1$

$$
f\left(v_{i}\right)=f\left(u_{i}\right)= \begin{cases}1, & \text { if } i \equiv 1(\bmod 2) \\ 2, & \text { if } i \equiv 0(\bmod 2)\end{cases}
$$

For $1 \leq i \leq n-2$

$$
f\left(v_{i} v_{i+1}\right)= \begin{cases}3, & \text { if } i \equiv 1(\bmod 2) \\ 4, & \text { if } i \equiv 0(\bmod 2)\end{cases}
$$

and $f\left(v_{n}\right)=4, f\left(v_{n} v_{1}\right)=2, f\left(v_{n-1} v_{n}\right)=1$

For $1 \leq i \leq n-1$

$$
f\left(v_{i} u_{i+1}\right)=f\left(v_{n} u_{1}\right)=5, f\left(v_{i+1} u_{i}\right)=f\left(v_{1} u_{n}\right)=6
$$

For $1 \leq i \leq n$

$$
f\left(v_{i}^{\prime}\right)=f\left(u_{i}^{\prime}\right)=3, f\left(v_{i} v_{i}^{\prime}\right)=7 \text { and } f\left(u_{i} v_{i}^{\prime}\right)=f\left(v_{i} u_{i}^{\prime}\right)=8
$$

Case-2. If $n \equiv 0(\bmod 2)$.

For $1 \leq i \leq n$

For $1 \leq i \leq n-1$

$$
f\left(v_{i}\right)=f\left(u_{i}\right)= \begin{cases}1, & \text { if } i \equiv 1(\bmod 2) \\ 2, & \text { if } i \equiv 0(\bmod 2)\end{cases}
$$

$$
f\left(v_{i} v_{i+1}\right)=\left\{\begin{array}{ll}
3, & \text { if } i \equiv 1(\bmod 2) \\
4, & \text { if } i \equiv 0(\bmod 2)
\end{array} \text { and } f\left(v_{n} v_{1}\right)=4\right.
$$


Adjacent Vertex Distinguishing Total Coloring of Line and Splitting Graph of Some Graphs

For $1 \leq i \leq n-1, \quad f\left(v_{i} u_{i+1}\right)=f\left(v_{n} u_{1}\right)=5, f\left(v_{i+1} u_{i}\right)=f\left(v_{1} u_{n}\right)=6$

For $1 \leq i \leq n, f\left(v_{i}^{\prime}\right)=f\left(u_{i}^{\prime}\right)=3, f\left(v_{i} v_{i}^{\prime}\right)=7$ and $f\left(u_{i} v_{i}^{\prime}\right)=f\left(v_{i} u_{i}^{\prime}\right)=8$

$\therefore \quad \chi_{\text {avt }}\left(\operatorname{Sp}\left(S^{2 n}\right)\right)=8, n \geq 4$.

Therefore the splitting graph of sun let graph admits AVDTC conjecture. Hence the theorem.

\section{Conclusion}

We found the adjacent vertex distinguishing total chromatic number of line graph of Fan graph, double star, Friendship graph and splitting graph of path, cycle, star and sun let graph. Also, it is proved that the adjacent vertex distinguishing total coloring conjecture is true for these graphs.

Acknowledgement. The second author gratefully acknowledge The Department of Science and Technology, DST PURSE - Phase II for the financial support under the grant 686 (2014).

\section{REFERENCES}

1. N.L.Biggs, Algebraic Graph Theory, Cambridge University Press, $2^{\text {nd }}$ edition, Cambridge, 1993.

2. F.Harary, Graph Theory, Narosa publishing House. (2001).

3. N.Khan, M.Pal and A.Pal, (2,1)-total labelling of cactus graphs, Journal of Information and Computing Science, 5(4) (2010) 243-260.

4. N.Khan and M.Pal, Adjacent vertex distinguishing edge colouring of cactus graphs, International Journal of Engineering and Innovative Technology, 4(3) (2013) 62-71.

5. K.K.Parthasarathy, Basic Graph Theory, Tata McGraw Hill, (1994).

6. K.Thirusangu and R.Ezhilarasi, Adjacent-vertex- distinguishing total coloring of tensor product of graphs, communicated.

7. K.Thirusangu and R.Ezhilarasi, Adjacent vertex distinguishing total coloring of quadrilateral snake, Journal of Advances in Mathematics, 13 (1) (2017) 7030-7041.

8. Z.Zhang, X.Chen, L.Jingwen, B.Yao, X.Lu and J.Wang, On adjacent-vertexdistinguishing total coloring of graphs, Science in China Ser. A Mathematics, 48 (3) (2005) 289-299. 